\title{
Andrija Mohorovičić's investigation of the earthquake of 8.10.1909
}

\begin{abstract}
The outstanding Croatian geophysicist Andrija Mohorovičić (1857-1936), was Director of the Meteorological Observatory in Zagreb (from 1892), a Member of the Yugoslav Academy of the Arts and Sciences (from 1893), and Associate Professor at The University of Zagreb (from 1910). In 1893 he was awarded a doctorate in meteorology at The University of Zagreb. An excellent comprehensive account of his life and work has been published in Croatian and English by Skoko and Mokrović (1982).
\end{abstract}

A strong earthquake occurred in the

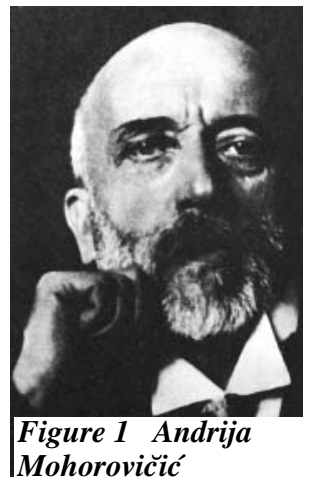
Kupa Valley, $39 \mathrm{~km}$ south of Zagreb, on 8

October, 1909, which was well recorded in the Geophysical Observatory at Zagreb and from which Mohorovičić collected much data. $\mathrm{He}$ also obtained macroseismic data from elsewhere in Croatia, and seismograms from all the European observatories. It was specially important that he received many observations from stations that were less than $800 \mathrm{~km}$ from the epicentre at the time of the earthquake. The large amount of data enabled him to contour the epicentral area very precisely and the numerous good-quality seismograms inspired 'a hope in him that he would be able to see more deeply into the mechanism of earthquake shock propagation' (p. 1). His hope was based on the fact that at that time good wave travel-time tables ('hodographs') were available for distances of between 1,000 and $10,000 \mathrm{~km}$ from an epicentre (Emil Wiechert and others). Those for smaller distances were not reliable, but the data from the 1909 earthquake in Croatia promised to make good this deficiency.

After close analysis of the data, Mohorovičić published his celebrated but rather little read paper, 'On the Earthquake of 8.10.1909', in 1910. This work, published simultaneously in Croatian and German, had the following sections: Foreword; 1. Introduction; 2. Epicentre of the earthquake of 8.10.1909; 3. Seismograms; 4. Propagation of waves in the uppermost layers of the Earth; 5. Normal Primary waves $(P) ; 6$. Transverse waves; 7 . Reflected waves in the uppermost layers of the Earth; 8. Further confirmations of the correctness of the theory; 9. Determination of the depth of the hypocentre; 10 . The influence of hypocentre depth on certain phases; 11. Concluding remarks.

Unfortunately, Mohorovičić published this major work in a local journal of rather small circulation, which issued only a few reprints. These, however, were exchanged with the major seismological observatories in Europe. Today the original text is a bibliographical rarity. Furthermore, Croatian and German are used today by only a limited number of researchers. This is why it is very important for contemporary science and for the history of our science to inform a wide circle of researchers about the nature of Mohorovičić's work. However, the size of the work (56 pages in Croatian alone) does not permit it to be presented in full, and not even in extended segments. Therefore the present paper proceeds chiefly by exposition, with only a limited number of direct quotations. It is a difficult task to present the author's arguments because the paper was originally written in the form of a narrative of the investigator's actual research process, with reference to all his ideas, dilemmas, trials, and solutions.

\section{Section I}

In his Introductory section (pp. 2-8) Mohorovičić discusses three of the main seismological theoretical problems of his day. These were: 1) the causes of the differences in the seismograms for the same earthquake obtained at different stations; 2) problems that occurred in the reading and interpretation of well-defined seismograms; and 3 ) the mode of propagation of earthquake waves through the Earth. It is specially interesting that in this introductory section the author gives certain arguments against the prevailing view that the main earthquake phase was represented only by 'surface waves' (pp. 7-8).

\section{Section II}

In the short second section (pp. 8-9) Mohorovičic describes the isoseismic lines of the Kupa Valley earthquake of 8 October, 1909, on the basis of macroseismic data and its epicentre was determined as being at a single point with coordinates $45^{\circ} 29^{\prime} \mathrm{N}$ and $16^{\circ} 03^{\prime} \mathrm{E}$.

\section{Section III}

Since wave travel-time tables are the foundation for every investigation of wave propagation Mohorovičić devoted this section to a detailed presentation of the process whereby he made his 'traveltime table diagram' (Table 1).

Mohorovicić precisely determined the epicentral time for the 1909 earthquake and the aftershocks. He then calculated the average travel-times for all types of waves for this earthquake to 29 observatories, from which he had obtained high-quality seismograms. He then plotted the data on a graph (with distances on the ordinate and times on the abscissa) in the form of dots and circles. Finally, he drew curves connecting the dots and circles on the diagram. Additionally, he used earthquake data from: Calabria (8 September, 1905); the Balkan Mountains (4 April, 1904); India (4 April, 1905); and two earthquakes of uncertain epicentre (for 1 June, 1905, and 8 November, 1905). He recalculated the data several times, fitting them to his curves; and in this way he corrected his wave travel-time curves until finally he obtained a very precise and absolutely new general 'travel-time table diagram' (Table 1; Figure 2 in the present text) for all close-range earthquakes. With this diagram Mohorovičić could give a direct answer to his principal question: what is the mechanism of wave propagation for close-range earthquakes? As usual, however, a large number of new questions appeared.

Contrary to all previous authors, Mohorovičic found that longitudinal and transverse waves were not singular. On his 'travel-time table diagram' they appeared as four separate curves (black bold lines) and were assigned special names (pp. 18, 38 and Table 1): normal or Lower [level] Primaries $(P)$, individual or upper [level] Primaries $(\bar{P})$, normal or Lower [level] Secondaries $(S)$ and Upper [level] Secondaries $(\bar{S})$. Mohorovičić described the general features of these waves and their wave travel-time curves (pp. 18, 22, and 23) and described the problems involved in their construction. In addition, he emphasised that they were not different longitudinal or transverse waves but were merely waves that had travelled from the same source by different pathways and consequently did not reach the stations at the same time (p. 34). Mohorovicić realised that those facts could not be interpreted in terms of the ideas about the uniformity of the Earth's interior that prevailed at that time.

\section{Section IV}

Discussing the propagation of earthquake waves in the uppermost 


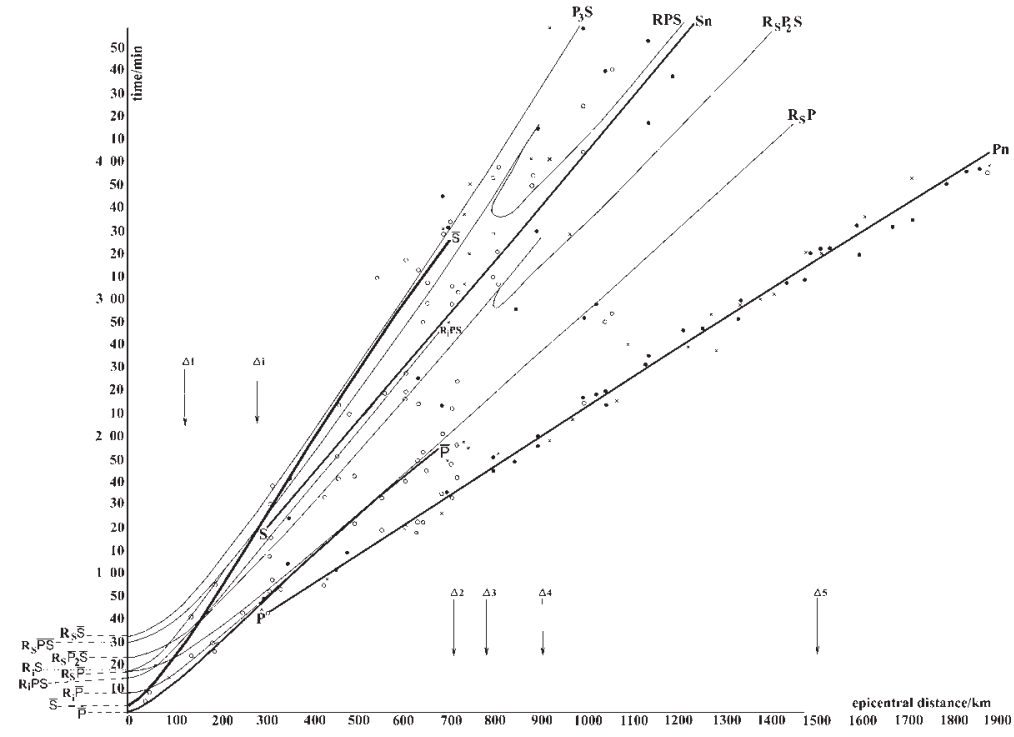

Figure 2 Diagram of Mohorovičic's theoretical travel-time table (Skoko \& Mokrovic' 1982).

layers of the Earth, Mohorovičić wrote (pp. 23-24):

When I...became aware that there are two types of firstarriving waves reaching places between 300 and $700 \mathrm{~km}$ from the epicentre, but only the first type arrives at places less than $300 \mathrm{~km}$, while for more than $700 \mathrm{~km}$ only the second type arrives, I tried to explain this previously unknown fact.

This became Mohorovičić's new main question. He then wrote: Since it is absolutely impossible that two different types of longitudinal waves can start from the hypocentre..., and since normal or Lower [level] Primary waves $(P)$ only make an appearance at a certain distance from the epicentre, I first looked for an explanation of the individual or Upper [level] Primaries $(\bar{P})$, which could be traced close to the epicentre.

Further, Mohorovičić wrote:

The attempt to calculate the depth of the hypocentre according to the hypothesis that the $P$ waves are uniformly propagated failed.... The calculation showed that the speed of propagation must slowly increase with depth.

The attempt to calculate the depth of the hypocentre by already known formulae for wave propagation also failed because the equations were too complicated.

From that point, Mohorovičić realised that he now had to continue his investigation on the basis of two completely new general premises. The first assumed that the velocity of seismic waves $(c)$ in the uppermost part of the Earth increased with depth, while the second was based on the assumption that at a certain depth $(d)$ there must be a bordering or boundary surface that separates the upper and lower parts of Earth.

Mohorovičic' next 'tried making some simple assumptions about the increase of velocity with depth, hoping that he would thereby discover some simple formula' (p. 24) for calculating the time of seismic waves' propagation. He controlled the 'approach to the truth' of his formulae by comparing the results of calculation with his wave travel-time curves. After several attempts, he reached the following starting position (p. 24):

Let $P_{0}$ be the radius vector from the Earth's centre to the hypocentre; let $P$ and $\Phi$ be the radius vector and angular distance of the appropriate point to which the ray of the earthquake travels during time $t$; let $c_{0}$ be the starting velocity at the hypocentre and let $c$ be the velocity at the point determined by $P, \Phi$ and $t$. At the same time, let $e_{0}$ and $e$ be the angles between the prolongation of the radius vector to the
Earth's surface and the direction where the wave is propagated in both points. If we assume that the velocity is a function of the radius vector, then the well-known formula for refraction is valid:

$$
\frac{1}{\mathrm{c}} \mathrm{P} \sin \mathrm{e}=\frac{1}{\mathrm{c}_{\mathrm{o}}} \mathrm{P}_{\mathrm{o}} \sin \mathrm{e}_{\mathrm{o}}=\mathrm{a}
$$

where $a$ is the propagation time of the refracted waves.

By further mathematical manipulation (pp. 24-25), substituting appropriate values, and making integrals, Mohorovičić arrived at an equation for the determination of the wave velocity at all observation points:

$$
\mathrm{c}=\mathrm{c}_{\mathrm{o}}\left(\frac{\mathrm{P}_{\mathrm{o}}}{\mathrm{P}}\right)^{\mathrm{k}}
$$

where $k$ is an exponent indicating the increase of velocity with depth.

After successfully establishing this simple equation (3), Mohorovičić, by suitable substitutions and integration, came to two new important equations (pp. 25 and 26), by means of which it was possible to find: the time $(t)$ of the wave travel from the hypocentre to some point on the Earth's surface (4); and the epicentral distance $(\Phi)$ of that point for various values of angle $e_{0}$ at the hypocentre (9):

$$
\begin{aligned}
& \mathbf{t}=\frac{\mathrm{P}}{(\mathrm{k}+1) \mathrm{c}_{0} \mathrm{r}^{\mathrm{k}}}\left[\sqrt{1-\mathrm{r}^{2(k+1)} \sin ^{2} \mathrm{e}_{\mathrm{o}}}-\mathrm{r}^{\mathrm{k}+1} \cos \mathrm{e}_{\mathrm{o}}\right] \\
& \Phi=\frac{1}{\mathrm{k}+1}\left[\mathrm{e}_{\mathrm{o}}-\arcsin \left\{\mathrm{r}^{\mathrm{k}+1} \sin \mathrm{e}_{\mathrm{o}}\right\}\right]
\end{aligned}
$$

where ' $r$ ' is the distance from the Earth's centre to the point at which the velocity ' $c$ ' is determined.

Returning to the problem of the hypocentre depth calculation (p. 27), Mohorovicić wrote: 'we have only the travel-time table at our disposal'. 'The shape of the curve from the station closest to the epicentre is known only as much as the accuracy of measurement from certain observatories allows. The [actual] shape of the curve from the epicentre to the closest station is unknown'. However, the time-difference is known from the moment the wave is recorded at certain stations and the epicentral distance of inflection is also known-in other words, the inflection is the point at which the travel-time curve changes from a concave to convex shape in the upward direction. On the basis of that empirical information, according to Mohorovičic, it is 'possible to determine the hypocentral depth with certainty' (p. 28).

In order to apply the theoretical travel-time curve 'it is necessary to determine three unknowns: $c_{0}, P_{0}$ and $k^{\prime}$ (p. 28). It is possible to obtain these by experiments only by systematic selection of values for these unknowns and the use of their combinations in equations until results that fit are obtained on the travel-time tables.

This task Mohorovičić finished by calculations and in tables (pp. 29-33), using the example of the earthquake in the Kupa Valley. The theoretical travel-time table best fitting the actual measurements from this shock was obtained with the following assumptions: that the hypocentre was located at a depth of $25 \mathrm{~km}$; that the original velocity $\left(\bar{P}-c_{0}\right)=5.60 \mathrm{~km} \mathrm{~s}^{-1}$; and that the exponent $k=3.0$. When he placed these values in Equations (4) and (9) he obtained a theoretical travel-time curve that had minimal discrepancy as compared with measured values. With much delight he concluded (pp. 32-33):

The average difference of both curves is smaller than the error in the time-curve construction.... The difference of both curves is so small that we may conclude that Equations (4) and (9) represent the time-curve very precisely in every detail.

With this Mohorovičić confirmed his first fundamental assumption about the increase of velocity of seismic waves with depth and also showed that it is possible to determine the depth of the hypocen- 
tre and calculate the seismic waves' velocity at any depth for which the exponential function law (Equation 3 ) is valid.

Towards the end of this section, Mohorovičić (pp. 33-34) started to deal with his initial problem: why do individual Primary waves disappear at a distance of about $720 \mathrm{~km}$ from the epicentre, and why is it that two longitudinal (and two transverse) waves reach some points? Treating those two questions, he wrote:

There was an earlier explanation as to why $\bar{P}$ possibly reached the distance of $720 \mathrm{~km} . .$. . We shall provisionally keep to this distance since all further hypotheses are based on the assumption that the curve ends somewhere.

If the end-point of the curve is $720 \mathrm{~km}$ from the epicentre than the wave ray reaches the lowest point on its route according to Equation (12) (p. 27):

$$
\mathrm{P}=\mathrm{P}_{\mathrm{o}} \mathrm{k}+\sqrt[1]{\sin \mathrm{e}_{\mathrm{o}}}
$$

which means that it reaches a depth of $54 \mathrm{~km}$ at distance $3^{\circ}$ $4^{\prime} 6^{\prime \prime}(411 \mathrm{~km})$. And if the largest impulse angle at the hypocentre is $100^{\circ}$ only, which fits to the final point of the curve at the distance of $666 \mathrm{~km}$, than the deepest point reached is $49 \mathrm{~km}$.

To hypothesise further I had to assume some depth that could be closely confirmed by observation. I decided to take the depth to be $50 \mathrm{~km}$.

There followed the most important conclusion of Mohorovic ić 's work (pp. 33-34):

Since $\bar{P}$ can reach only a depth of $50 \mathrm{~km}$ the boundary surface of the uppermost layer of the Earth is found at that depth. At that depth it must be that the material of which the Earth's interior is composed suddenly changes, because [at that depth] there is a sudden increase of earthquake wavevelocity.

\section{Section V}

In his fifth section, Mohorovičić determined that 'normal Primary [waves] are propagated in the Earth's interior at a much higher velocity than that of individual Primaries' (p. 34). Then he systematically chose different values for certain parameters $\left(\Phi, t, e, e_{0}, d, k\right.$ and $k_{l}$ ), made calculations using them, and obtained results that could be compared with the P curve on his travel-time table. On completing this complicated task (pp. 34-37) he was able to conclude that (p. 38):

All waves that start from the hypocentre between angles of $0^{\circ}$ and $133^{\circ} 49^{\prime}$ stay in the upper layer... Waves that leave the hypocentre at the angle of $133^{\circ} 49^{\prime}$ are reflected at the lower surface and appear at the Earth's surface at the distance of $79 \mathrm{~km}$.

However, among the waves that penetrate into the Earth's interior: only the few waves that leave the hypocentre at a somewhat greater angle [and can be refracted] reach the

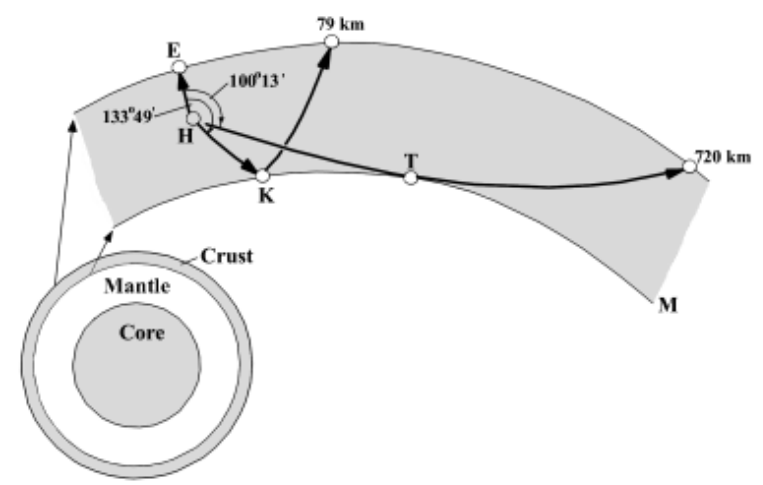

Figure 3 Waves whose rays emerge from the focus at an angle $e_{h}$ between $0^{\circ}$ and $100^{\circ} 13^{\prime}$, pass through the Earth's crust and produce, on seismograms, the $\bar{P}$ and $\bar{S}$ phases of longitudinal and transverse waves (Skoko and Mokrovic, 1982, p. 114).
Earth's surface... This is why the phenomenon that normal Primary waves are registered only at greater distances from the epicentre is explained by the need for the wave to reach the lower surface of the upper layer [of the Earth] at such an angle that refraction is possible.

\section{Section VI}

After dealing with longitudinal waves, Mohorovičić went on to investigate transverse seismic waves. He had concluded that:

both wave-types, individual and normal Primaries, are of just one type, which differ one from another only by the fact that they travel by different routes to the Earth's surface. This means that both types are longitudinal waves (p. 38).

Mohorovičić then distinguished two types of transverse wave: transverse (Secondaries) of individual Primaries $(\bar{S})$ and transverse (Secondaries) of normal Primaries $(S)$. He assumed that the 'main earthquake phase' is in fact produced by transverse waves associated with normal Primaries (p. 38). He determined also that there are differences in the longitudinal and transverse wave velocities. For the latter, he derived similar mathematical and combinational investigations and made comparisons with travel-time curves (pp. 39-41), as had been done for the longitudinal waves.

It is important to remark that Mohorovičic discovered that the transverse wave velocity in the Earth's uppermost layer increases with depth from $3.23 \mathrm{~km} \mathrm{~s}^{-1}$ at the surface to $3.32 \mathrm{~s}^{-1}$ at its lower boundary (pp. 40-41). On passing through that boundary surface the speed increased radically to $4.182 \mathrm{~km} \mathrm{~s}^{-1}$.

\section{Section VII}

Since Mohorovičić had given a proof in his previous section that 'at an important depth of some $50 \mathrm{~km}$ there is a surface where strong wave refraction occurs' he concluded that 'at this surface, as also at the Earth's surface, various wave reflections must occur' in the Earth's uppermost layer (p. 42). He further wrote:

Two types of reflections may occur:

a) a lower reflection $\left(R_{i}\right)$ where every ray reaches the Earth's surface after being previously reflected from the lower surface,

b) an upper reflection $\left(R_{S}\right)$ where every ray reaches the Earth's surface after being previously reflected from the upper and then the lower surface.

Those two kinds of reflection may be repeated as many times as are needed to dissipate all the initial energy.

Various changes may occur upon reflections of $L$ (longitudinal) waves into $S$ (transverse) waves and viceversa, so that we may get several time-curves instead of only two (p. 42).

Following this, Mohorovič ić reviewed which kinds of waves might originate from the $R_{i}\left(\alpha, \beta\right.$ and $\gamma$ cases) and $R_{S}(\alpha, \beta, \gamma$ and $\delta$ cases) types of reflections, and he assumed that: 'as reflection is repeated the number of possible travel-time curves is increased' ( $p$. 43). Finally Mohorovičić calculated (pp. 44 and 45) and drew (Table 1) travel-time curves for seven cases of reflection. ( $R s \bar{S}, R s \bar{P} S_{2}$, $\operatorname{Rs}_{\bar{P}} S, \operatorname{Ri} \bar{S}, R s \bar{P}, \operatorname{Ri} \bar{P} \bar{S}$, and $\left.R i \bar{P}\right)$, using pre-defined tables with calculated wave pathways and travel-times (pp. 44-46).

\section{Section VIII}

The whole of the eighth section (pp. 46-52) is dedicated to proofs that reflected waves really exist. Mohorovičić first discovered all the aforementioned phases on seismograms of earthquakes that occurred on 13 December, 1909, and 28 January, 1910, from observatories in Vienna, Munich, Toronto, Jena, Leipzig, and Strasbourg. Then he observed reflections on the seismograms of 15 earthquakes recorded in Zagreb in 1908, 1909, and 1910. Finally, he wrote decisively (p. 52):

From the given examples it can be observed that reflections really do exist and that they can be found in valid earthquake recordings. Between 300 and $700 \mathrm{~km}$ we see them in all seismograms. 
He added also his practical experience: It is much easier to find reflections in weak earthquakes than in strong ones, because in the former only the first reflections occur.

\section{Section IX}

In his ninth section, Mohorovičić gave a critical review of contemporary mathematical methods for calculating the hypocentre distance (pp. 52-53) and recommended that (p. 54):

The best method of distance calculation includes means whereby all the recorded phases are compared with the travel-time curves. In close-range earthquakes we first read all the strong deviations and the time differences between them and we mark the first deviation on the ruler with a millimetre gauge. Than we move the ruler over the travel-time table diagram until all, or at least most, of the phases fit to the travel-time curves. Then we have obtained the most probable distance.

\section{Section $\mathbf{X}$}

According to Mohorovicić, the hypocentre depth influences the coordinates $\Phi$, then the inflection point position, and... the distance that is reached by the waves that are reflected...from the lower boundary of the Earth's uppermost layer. Because of that, travel-time curves are being changed for the $L$ and $S$ waves.

Additionally he made the interesting assumption that: 'If the hypocentre lies in the lower layer of the Earth then the earthquake would have neither $\bar{P}$ nor $\bar{S}$; it would therefore be an earthquake without the maximal phase'. But in saying this 'I have to assume that in the lower layer of the Earth there are no seismic activities' (pp. 54-55).

\section{Section XI}

Finally, after all his assumptions and calculations, Mohorovičić wrote that by means of his Equation (3) it was possible to calculate the velocity of seismic waves very accurately, and Equations (4) and (9) gave satisfactory results for all wave travel-times within the limits of precision that could be achieved at that time. Than he underlined the point that numerous earthquake data analyses would need to be performed before the problem of wave propagation could be completely solved. For this reason, he recommended that all observatories should take great care about the accuracy of their earthquake recordings (which involved the quality of their chronometers and the uniformity of the rate of rotation of the recording paper of their instruments) and that with close-range earthquakes (up to $2000 \mathrm{~km}$ ) they should read all the visible stronger deviations and period changes, as well as the main phases. This would greatly assist further investigations of seismic wave propagation in the Earth's uppermost layer. 'This [paper] should be considered only as the first attempt' (p. 56).

$$
* \quad * \quad * \quad *
$$

Particular travel-time tables for individual earthquakes, and theoretical travel-time tables for longitudinal, transverse, and surface waves, had already been compiled and published (Oldham, 1906; Milne, 1903; Imanura, 1904; Rizzo, 1906; Benndorf, 1905; 1906,
Zoeppritz, 1907; etc.) before Mohorovičić's work, but he was the first person to make theoretical travel-time tables for close-range earthquakes and differentiate on them precisely all phases of the Primary, Secondary, and reflected wave positions. Wiechert (1906) had hypothesised that the Earth's interior consisted of several homogenous concentric layers, but it was Mohorovičić who was the first to demonstrate this by the use of precise and accurate empirical data. While solving these problems, Mohorovičić used published seismograms from various earthquakes, but the motive and foundation for the whole investigation were data recorded from the Kupa Valley earthquake of 8 October, 1909. For this reason, this earthquake is cited as a classic in all seismology textbooks, and Mohorovič ić's investigation led to a 'turning-point' publication in the history of seismology, and indeed for the whole of geology.

The great importance of Mohorovičić's work was first recognised by the Gratz seismologist Hans Benndorf (1912). He emphasised that it was one of the most important seismological publications, though he made a number of critical remarks about the reported results. Beno Gutenberg (1915) confirmed Mohorovičić's discovery.

Mohorovičić continued his work: he constructed and improved his travel-time tables for large epicentral distances; contributed to methods for the precise location of the epicentres of earthquakes, drawing so-called 'Mohorovič ić epicentrals'; constructed a new, more sensitive seismograph; made a systematic study of the influence of earthquakes on buildings, etc.

Mohorovičić's work proved that it was possible to investigate the Earth's interior by means of seismic waves and for this reason, and because of his many other contributions, the boundary surface between Earth's crust and mantle was given the name of Mohorovičić discontinuity', or 'Moho' for short (A.F. Birch, 1952). In addition, Equation (3), usually given today in the form $\mathrm{c}=\mathrm{c}_{\mathrm{h}}\left(\mathrm{r}_{\mathrm{h}} / \mathrm{r}\right)^{\mathrm{k}}$, is named Mohorovičić's Law (Skoko \& Mokrović, 1982, p. 109).

\section{Acknowledgment}

I am most grateful to David Oldroyd, Secretary-General of INHIGEO, for his editorial assistance in completing this paper.

\section{References}

Birch, A.F., 1952, Elasticity and constitution of the Earth's interior: Journal of Geophysical Research, v. 57, pp. 227-286.

Mohorovičić, A., 1910, Das Beben vom 8.X.1909: Jahrbuch des Meteorologischen Observatoriums in Zagreb (Agram), fuer das Jahr 1909, v. 9 (part 4, section 1), pp. 1-63.

Skoko, D. and Mokrović, J., 1982, Andrija Mohorovičić: Biography and Scientific Work: Skolska knjiga, Zagreb.

\section{Aleksandar Grubic}

The Faculty of Geology and Mining

Belgrade University

Dusina 7, Belgrade

YUGOSLAVIA 
